and sharing medical knowledge.

Citizen groups have a growing role in this. In Cambodia, MoPoTsyo, a nonprofit organization in Phnom Penh for people with diabetes or high blood pressure, helps members to manage their disease and to negotiate with physicians and pharmacists. Organizations that are trusted by communities, such as faithbased hospitals and social entrepreneurs, are also engaging with health markets.

Mobile telephones are creating new opportunities for linking patients, informal providers and trained physicians. In Bangladesh, for example, mobile phones are being used to relay information about treatments, drug side effects and the management of chronic diseases. The impact of new technologies on health markets is difficult to predict or plan for, but services for vulnerable populations can usually be improved if interventions are tailored to their needs, and the results are shared among patients, providers and policy-makers ${ }^{6}$.

As in other complex systems, a single intervention is unlikely to lead to sustainable change, so players will need to experiment, adapt and learn. Strategies that could be tested by governments and the medical profession include the formal accreditation or licensing of new categories of health workers. Arrangements for public-sector doctors who supplement their income through private practice should be made transparent.

The urgent need is to protect the poor who rely on unregulated health markets. In the longer term, everyone's health depends on rising to this challenge.

David H. Peters is director of the Health Systems Program, Department of International Health, Johns Hopkins Bloomberg School of Public Health, Baltimore, Maryland 21205, USA. Gerald Bloom is a fellow at the Institute of Development Studies, University of Sussex, Brighton BN1 9RE, UK. e-mails:dpeters@jhsph.edu; g.bloom@ids.ac.uk

1. Bloom, G., Kanjilal, B., Lucas, H. \& Peters, D. (eds) Transforming Health Markets in Asia and Africa: Improving Quality and Access for the Poor (Routledge, in the press).

2. World Health Organization. Medicines Use in Primary Care in Developing and Transitional Countries (WHO, 2009).

3. World Health Organization. The World Health Report 2006 (WHO, 2006).

4. Newton, P. N. et al. PLoS Med. 5, e32 (2008).

5. Paina, L \& Peters, D. H. Health Policy Plan. http://dx.doi.org/10.1093/heapol/czr054 (2011).

6. Peters, D. H., El-Saharty, S., Siadat, B., Janovsky, K. \& Vujicic, M. (eds) Improving Health Service Delivery in Developing Countries: From Evidence to Action (The World Bank, 2009).

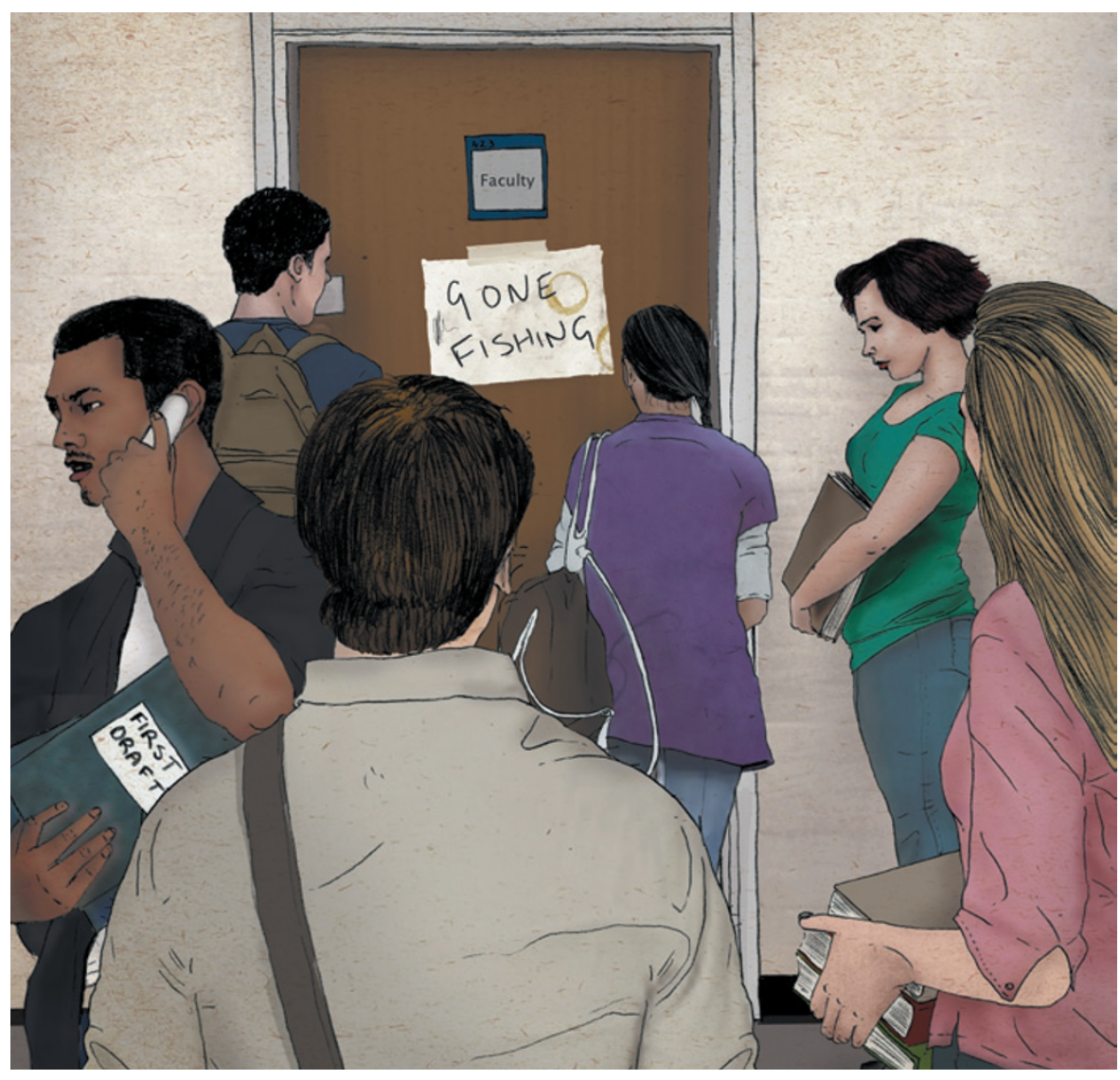

\title{
Make mentorship
}

matter

\section{John M. Braxton calls for teaching-integrity committees to deal with academics who fail in their responsibilities.}

$\mathrm{M}$ isconduct is a word that is always on professors' minds. Incidents in the news tend to describe the most serious violations of scientific standards, such as plagiarism or fabricating data. But these high-profile infractions occur relatively rarely. Much more frequent are forms of misconduct that occur as part of the intimate relationship between a faculty member and a student.

Faculty members don't need to commit egregious acts such as sexual harassment or appropriation of students' work to fail in their responsibility to their charges. Being generally negligent as teachers and mentors should also be seen as falling down on the job.

To assess faculty members' attitudes towards these more subtle behaviours, starting a few years ago, my colleagues (Eve Proper, Alan Bayer) and I mailed a questionnaire to more than 3,500 US faculty members in science (biology, chemistry and psychology) and history. Approximately 800 people (23\%) responded. (Although the response rate was lower than we had hoped, an analysis of people who responded to a second mailing of the survey showed that they shared similar demographics and perceptions of the main behaviours with people who responded to the first mailing, suggesting that this first group is likely to be representative of the entire group.)

The questions focused on more than 120 types of behaviour, asking respondents to rate them from 1 to 5 , with 1 being appropriate behaviour that should be encouraged, and 5 being totally unacceptable actions requiring formal administrative intervention (J.M. Braxton, E. Proper and A. E. Bayer Professors Behaving Badly Johns Hopkins University Press, 2011). Our findings were alarming.

Not surprisingly, respondents generally agreed on the most egregious behaviours, concurring that faculty members should never disrespect students' efforts, misappropriate their work, harass them or encourage misconduct (see 'Measure of a mentor').

What we found most interesting was how respondents had less-vehement reactions to a host of questionable behaviours. In particular, they said that faculty members should avoid - but not necessarily be punished 


\section{How US academics rated teaching behaviours.}

\author{
Egregious behaviours: \\ - Misappropriating a student's work. \\ - Routinely borrowing money from \\ advisees. \\ - Asking students to perform personal \\ chores, such as babysitting or household \\ errands. \\ - Making suggestive sexual comments or \\ sexist or racist remarks to students. \\ - Attending class while intoxicated. \\ - Instructing students to engage in \\ misconduct. \\ - Delaying graduation of the best graduate \\ students to keep them in the lab.
}

Generally ignorable behaviours:

- Being routinely late for classes.

- Ignoring the course outline for a seminar.

- Taking on more advisees than the

professor has time for.

lgnoring students with differing research

and academic interests.

- Routinely missing appointments set up

by the graduate advisee.

- Failing to provide substantive, timely

feedback about a thesis or dissertation.

- Routinely requiring students to work

longer hours than specified by the

institution. for - neglectful teaching and mentoring. These included routinely being late for classes, frequently skipping appointments with advisees, showing favouritism to some students, ignoring those whose interests diverged from their own, belittling colleagues in front of students, providing little to no feedback on students' theses or dissertations, and taking on more graduate advisees than they could handle. On average, respondents rated these behaviours as a 3 - mildly inappropriate, generally to be ignored.

The vast majority of US faculty members have simply not been taught how to teach. And these responses suggest that they are subjecting young scientists-in-training to the same neglect.

To address this systemic issue, we must do a better job of exposing the current and next generations of scientists to the rules of proper mentoring - through seminars, for instance, or online modules. The societies of academic disciplines, institutions and individual departments can play a big part here, by developing codes of conduct and clear mechanisms for students to report violations.

The most serious behaviours are relatively easy to spot and address, but 'inadequate teaching' can be subjective. Still, if universities establish specific rules for academics to follow, real patterns of abuse will be easier to find. For instance, these rules could stipulate that professors must return substantive feedback on drafts within 15 days, provide more than just negative feedback during a student's oral defence of their thesis, or be available regularly to answer questions.

To deal with faculty members who consistently fall short, universities should establish teaching-integrity committees, similar to the research-integrity committees that handle issues of scientific misconduct. These could receive reports from students and decide what action to take, either by following a due process laid out in the faculty manual, or simply by adopting the same process as that of other committees, such as for tenure applications.

There should be clearly established sanctions for inadequate teaching and mentoring, such as warnings, reprimands, public censures, changes to salary - and, in the most severe cases, suspension or termination. Of course, the proceedings of such committees must assure confidentiality for both the accused and the accuser. And faculty members shouldn't just be punished for bad mentoring - there should be some rewards in place for those who consistently take this part of their job seriously.

Less formally, professors must be good role models for graduate students, who are constantly observing and listening for cues on how to become scientists. This includes avoiding unprofessional, off-hand comments in class or to colleagues, which students often absorb. Faculty members should talk to their students about misconduct incidents that they have seen or read about. My department, for instance, has regular seminars for students and academics designed for just this purpose.

It is in the best interest of universities to give mentorship more consideration. Students who are well trained will become more successful, reflecting well on their previous institutions. More importantly, the research enterprise owes it to the next generation to make them the best scientists they can be and enable them, in turn, to mentor an even stronger group to eventually replace them.

These suggestions are not meant to reduce the autonomy of faculty members, which is key to protecting academic freedom. But with autonomy comes responsibility - and faculty members have to start taking it much more seriously.

John M. Braxton is professor of education at Vanderbilt University, Nashville, Tennessee 37203, USA. e-mail:john.braxton@vanderbilt.edu 